\section{SAT0324 CERTOLIZUMAB PEGOL PROVIDES SUSTAINED REMISSION AND MINIMAL DISEASE ACTIVITY IN PATIENTS WITH PSORIATIC ARTHRITIS OVER 4 YEARS' TREATMENT}

D. van der Heijde ${ }^{1}$, A. Deodhar ${ }^{2}$, O. FitzGerald ${ }^{3}$, R. Fleischmann ${ }^{4}$, D. Gladman ${ }^{5}$, A. B. Gottlieb ${ }^{6}$, L.C. Coates ${ }^{7}$, B. Hoepken ${ }^{8}$, L. Bauer ${ }^{8}$, L. Peterson ${ }^{9}$, M. Khraishi ${ }^{10}$, P. J. Mease ${ }^{11}$. Leiden University Medical Centre, Leiden, Netherlands; ${ }^{2}$ Oregon Health and Science University, Portland, OR, USA; ${ }^{3}$ St Vincent's University Hospital and Conway Institute for Biomolecular Research, University College Dublin, Dublin, Ireland; ${ }^{4}$ University of Texas Southwestern Medical Center, Dallas, TX, USA; ${ }^{5}$ Centre for Prognosis Studies in The Rheumatic Diseases and Krembil Research Institute, Toronto Western Hospital, Toronto, Canada; ${ }^{6}$ Department of Dermatology, New York Medical College at Metropolitan Hospital, New York, NY, USA; ${ }^{7}$ Nuffield Orthopaedic Centre, Oxford, UK; ${ }^{8}$ UCB Pharma, Monheim, Germany, ${ }^{9}$ UCB Pharma, Raleigh, NC, USA; ${ }^{10}$ Department of Medicine, Memorial University of Newfoundland, St John's, Canada; ${ }^{11}$ Swedish Medical Center and University of Washington, Seattle, WA, USA

Background: Disease Activity Index for Psoriatic Arthritis (DAPSA) ${ }^{1}$ and the minimal disease activity (MDA) criteria ${ }^{2}$ are instruments recommended for evaluating disease activity in psoriatic arthritis (PsA). The RAPID-PsA trial (NCT01087788) has demonstrated the sustained efficacy of certolizumab pegol (CZP) across the spectrum of PsA symptoms. ${ }^{3,4}$

Objectives: To report the proportion of CZP-treated patients (pts) achieving DAPSA remission (REM), DAPSA low disease activity (LDA), MDA (fulfilling $\geq 5 / 7$ MDA criteria), and very low disease activity (VLDA; fulfilling $7 / 7$ MDA criteria) over 216 weeks (wks) in RAPID-PsA.

Methods: RAPID-PsA was double-blind and placebo-controlled to Wk24, doseblind to Wk48, and open-label (OL) to Wk216. Pts had active PsA and had failed $\geq 1$ disease modifying anti-rheumatic drug. Data for pts randomised to CZP at Wk0 (200 mg every 2 wks or $400 \mathrm{mg}$ every 4 wks, following a $400 \mathrm{mg}$ loading dose at Wks0, 2, 4), who continued their assigned dose in the OL period, are presented as observed case and with imputation (figure 1). Outcomes reported are DAPSA (the sum of tender and swollen joint counts [TJC 68; SJC 66], pt global and pain assessment [10 $\mathrm{cm}$ visual analogue scale], and C-reactive protein levels [mg/dL]), and pts achieving: 1) DAPSA LDA (DAPSA $>4$ and $\leq 14$ ); 2) DAPSA REM (DAPSA $\leq 4$ ); 3) MDA (fulfilling $\geq 5 / 7$ MDA criteria); and 4) VLDA (fulfilling 7/7 MDA criteria), to Wk216. Pts withdrawing from the study between scheduled visits had their final observed assessment values assigned to the next scheduled visit timepoint.

Results: Of 409 pts randomised; 273 received CZP from Wk0, of whom 248 (90.8\%) completed Wk24, 237 (86.8\%) completed Wk48, and 183 (67.0\%) completed Wk216. The mean (SD) baseline DAPSA was 44.8 (22.9). Of pts completing Wk24, 29.7\% (74/249) achieved LDA; 25.3\% (63/249) REM; 38.2\% (95/249) MDA; and $14.9 \%(37 / 249)$ VLDA. At Wk216, 31.9\% (59/185) achieved LDA; $44.3 \%$ (82/185) REM; $57.8 \%$ (107/185) MDA; and 29.0\% (58/183) VLDA (figure 1).

Figure: A) Patients with PSA achieving DAPSA LDA and REM over 4 years' CZP treatment

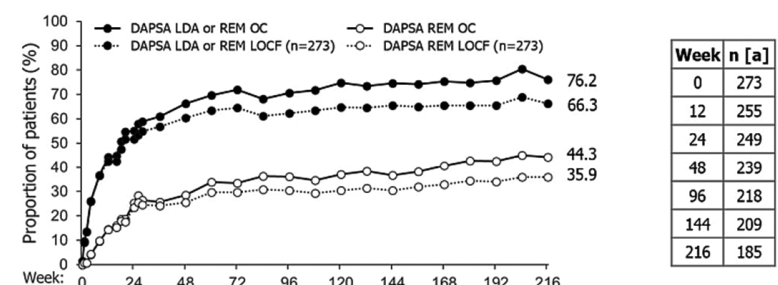

B) Patients with PsA achieving MDA and VLDA over 4 years' CZP treatment

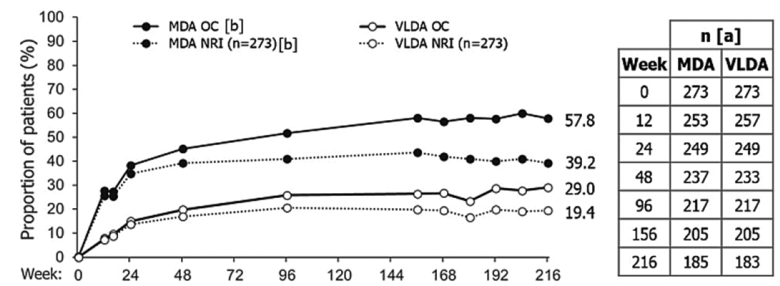

Data shown for the Randomized Set, for pts on either dose regimen. OC proportions are calculated as the number
achieving the target relative to the number of pts assessed at that timepoint. Missing values were imputed using LOCF for achieving the target relative to the number of pts assessed at that timepoint. Missing values were imputed using LOCCF for
DAPSA and NRI for MDA criteria. [a] Number of patients with an observed value at the scheduled visit timepoint; [b] The

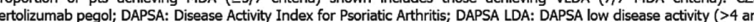
certolizumab pegol; DAPSA: Disease Activity Index for Psoriatic Arthritis; DAPSA LDA: DAPSA low disease activity (>4 and
$\leq 14$; DASA remission: DPASA REM (S4); LCCF: last observation carried forward, ; MA: minimal disease activity; NRI
non-responder imputation; OC: observed case; PSA: Psoriatic arthritis; pt: patient; VLDA: very low disease activity.

Abstract SAT0324 - Figure 1. A) Patients with PsA achieving DAPSA LDA and REM over 4 years' CZP treatment. B) Patients with PSA achieving MDA and VLDA over 4 years' CZP treatment
Conclusions: A substantial proportion of pts who completed the 4 year study achieved disease inactivity targets: 75\% achieved DAPSA LDA or REM, almost $60 \%$ achieved MDA, and half of those also achieved VLDA.

\section{REFERENCES:}

[1] Schoels MM. Ann Rheum Dis 2016;75(5):811-18.

[2] Coates LC. Ann Rheum Dis 2010;69(01):48-53.

[3] Mease PJ. Ann Rheum Dis 2016;75:608.

[4] FitzGerald O. JAAD 2017;76(6):AB264.

Acknowledgements: This study was funded by UCB Pharma. We thank the patients and their caregivers in addition to the investigators and their teams who contributed to this study. Editorial services were provided by Costello Medical. Disclosure of Interest: D. van der Heijde Consultant for: AbbVie, Amgen, Astellas, AstraZeneca, Bristol-Myers Squibb, Boehringer Ingelheim, Celgene, Daiichi, Eli Lilly, Galapagos, Gilead, Janssen, Merck, Novartis, Pfizer, Regeneron, Roche, Sanofi-Aventis, UCB Pharma, Employee of: Director of Imaging Rheumatology B. V., A. Deodhar Grant/research support from: AbbVie, Amgen, Eli Lilly, GlaxoSmithKline, Janssen, Novartis, Pfizer, UCB Pharma, Consultant for: Eli Lilly, Janssen, Novartis, Pfizer, UCB Pharma, O. FitzGerald Grant/research support from: AbbVie, Bristol-Myers Squibb, Janssen, Pfizer, Consultant for: AbbVie, Celgene, Amgen, Eli Lilly, Janssen, Pfizer, UCB Pharma, Speakers bureau: AbbVie, Celgene, Janssen, Novartis, Pfizer, UCB Pharma, R. Fleischmann Grant/research support from: AbbVie, Amgen, AstraZeneca, Bristol-Myers Squibb, Celgene, Eli Lilly, Genentech, Janssen, MSD Pharmaceuticals, Novartis, Pfizer, Roche, Sanofi-Aventis, UCB Pharma, Consultant for: AbbVie, Amgen, Bristol-Myers Squibb, Eli Lilly, GlaxoSmithKline, Janssen, Novartis, Pfizer, Sanofi-Aventis, D. Gladman Grant/research support from: Abbott, Amgen, Bristol-Myers Squibb, Celgene, Johnson and Johnson, MSD, Novartis, Pfizer, UCB Pharma, Consultant for: Abbott, Bristol-Myers Squibb, Celgene, Johnson and Johnson, MSD, Novartis, Pfizer, UCB Pharma, A. Gottlieb Grant/research support from: Abbott, Aclaris, Actelion, Akros, Amiscus, Amgen, Astellas, Baxalta, Beiersdorf, Bristol-Myers Squibb, Canfite, Catabasis, Celgene, Coronado, Crescendo Bioscience, CSL Behring Biotherapies for Life, Dermipsor, Dermira, Eli Lilly, Genentech, GlaxoSmithKline, Incyte, Janssen, Karyopharm, KinetaOne, KPI Therapeutics, Levia, Meiji Seika Pharma Co., Merck, Mitsubishi Tanabe, Novartis, Novo Nordisk, Pfizer, Reddy, Takeda, TEVA, UCB Pharma, Vertex, Xenoport, Consultant for: Abbott, Aclaris, Actelion, Akros, Amiscus, Amgen, Astellas, Baxalta, Beiersdorf, Bristol-Myers Squibb, Canfite, Catabasis, Celgene, Coronado, Crescendo Bioscience, CSL Behring Biotherapies for Life, Dermipsor, Dermira, Eli Lilly, Genentech, GlaxoSmithKline, Incyte, Janssen, Karyopharm, KinetaOne, KPI Therapeutics, Levia, Meiji Seika Pharma Co., Merck, Mitsubishi Tanabe, Novartis, Novo Nordisk, Pfizer, Reddy, Takeda, TEVA, UCB Pharma, Vertex, Xenoport, L. Coates Grant/research support from: AbbVie, Janssen, Novartis, Pfizer, Consultant for: AbbVie, Amgen, Bristol-Myers Squibb, Celgene, Eli Lilly, Janssen, MSD, Novartis, Pfizer, Prothena, Sun Pharma, UCB Pharma, B. Hoepken Employee of: UCB Pharma, L. Bauer Employee of: UCB Pharma, L. Peterson Employee of UCB Pharma, M. Khraishi Grant/research support from: Abbott, Amgen, Pfizer, Consultant for: Abbott, Amgen, Pfizer, P. Mease Grant/research support from: AbbVie, Amgen, Bristol-Myers Squibb, Celgene, Janssen, Eli Lilly, Novartis, Pfizer, Sun, UCB Pharma, Consultant for: AbbVie, Amgen, Bristol-Myers Squibb, Celgene, Janssen, Eli Lilly, Novartis, Pfizer, Sun, UCB Pharma, Speakers bureau: AbbVie, Amgen, Bristol-Myers Squibb, Celgene, Genentech, Janssen, Novartis, Pfizer, UCB Pharma

DOI: 10.1136/annrheumdis-2018-eular.2637

\section{SAT0325 COMPARATIVE ANALYSIS OF GENDER DIFFERENCES, HLA-B27 STATUS AND SKIN LESION SEVERITY IN EARLY AXIAL AND PERIPHERAL PSORIATIC ARTHRITIS PATIENTS}

E.E. Gubar, E.Y. Loginova, T.V. Korotaeva, S.I. Glukhova. V.A. Nasonova Research Institute of Rheumatology, Moscow, Russian Federation

Background: Clinical features of axial involvement in psoriatic arthritis (PsA) had been studied before only at advanced stages. Skin lesion severity, HLA-B27 status and gender-specific differences in early PsA patients with axial involvement hadn't been sufficiently studied.

Objectives: To compare clinical features of two early peripheral PsA patient pop ulations - with and without axial involvement.

Methods: 95 patients (pts) (M/F-47/48) with early PsA according to CASPAR criteria were included; all pts had peripheral arthritis for $\leq 2$ years; no inflammatory back pain (IBP) pts were specially selected. Mean age $36.5 \pm 10.7$ years, disease duration $12.2 \pm 10.3 \mathrm{mo}$, disease activity indexes $\mathrm{DAS}=4.0 \pm 1.4$, DAS28 $=4.2 \pm 1.1$, BASDAl $=4.5 \pm 1.6$ (in pts with axial involvement); patient's global disease activity (PGA) VAS $56.9 \pm 17.1$. All pts were evaluated for the presence of inflammatory 